Gut, 1972, 13, 361-365

\title{
Inhibition of pancreatic secretion in man by cigarette smoking
}

\author{
T. E. BYNUM, TRAVIS E. SOLOMON, LEONARD R. JOHNSON, AND EUGENE \\ D. JACOBSON
}

From the Departments of Medicine, Physiology, and Biophysics, University of Oklahamo Medical Center, Oklahoma City, Oklahoma, and the Texas Medical Center, Houston, Texas

SUMMARY Cigarette smoking has been linked to an elevated incidence of duodenal ulcer disease in smokers, although the mechanism is unclear. In 23 young normal subjects single or double secretin tests were performed during non-smoking and smoking periods. Cigarette smoking inhibited the secretion of pancreatic juice and bicarbonate in light smokers ( $<$ one pack/day for $<$ three years). Heavy smokers ( $>$ one pack/day for $>$ three years) exhibited depressed pancreatic secretory rates during non-smoking periods. Inhibition of pancreatic alkaline secretion by cigarette smoking could be the link between the habit and duodenal ulcer disease.

Most physicians advise against cigarette smoking for patients with peptic ulcer. This recommendation is based upon clinical impressions and a demonstrated increase in the incidence of peptic ulcer disease in smokers compared to a similar nonsmoking population (Doll, Jones, and Pygott, 1958). However, there is conflicting and inconsistent evidence concerning effects of cigarette smoke on gastric acid secretion in man (Piper and Raine, 1959; Debas, Cohen, Holubitsky, and Harrison, 1971; Wilkinson and Johnston, 1971), and epidemiological studies have not clarified the relationship between smoking and ulcer formation (Edwards, McKeown, and Whitfield, 1959; Hammond, 1964; Monson, 1970).

Recent studies (Konturek, Solomon, McCreight, Johnson, and Jacobson, 1971) from our laboratory have shown that nicotine inhibits pancreatic and biliary secretion of fluid and bicarbonate in conscious dogs. Since alkaline pancreatic secretion is the major buffer of gastric acid entering the duodenum, this inhibition of the pancreas by nicotine could be an important factor in the genesis of duodenal ulcer. Many investigators (Toon, Cross, and Wangensteen, 1951; Lee and Gruber, 1962; Robert, Stow, and Nezamis, 1972; Konturek, Rodecki, Thor, et al, 1972) have found that cigarette smoke and nicotine reinforce the action of agents causing experimental ulcers in animals.

Correspondence: Dr T. E. Bynum, Department of Medicine, Baylor College of Medicine, Texas Medical Center, Houston, Texas 77025.

Received for publication 29 February 1972.
Our report demonstrates that cigarette smoking inhibits pancreatic secretion in human subjects.

\section{Methods}

1 CONTROL GROUP

All five subjects in the control group were healthy young males ranging from 22 to 37 years of age. They had never smoked regularly at any time in their lives. These subjects underwent a single standard secretin test using Boots secretin. The procedure was as described for the first part of the double secretin test technique (details below).

\section{TEST GROUP}

Double secretin tests (Dreiling, Janowitz, and Halpern, 1955; Dreiling and Janowitz, 1960) were performed on 18 healthy subjects who were established cigarette smokers; nine were classified as light smokers (less than one pack of cigarettes per day for less than three years) and nine were designated heavy smokers (more than one pack of cigarettes per day for more than three years). Light smokers consisted of seven males and two females ranging from 15 to 26 years of age (mean 21 years). Heavy smokers consisted of eight males and one female ranging from 21 to 36 years of age (mean 26 years). All subjects were in good health with no evidence of previous pulmonary, cardiovascular, or gastrointestinal disorders. No subject was receiving medication.

The subjects did not smoke for 24 hours before the 
test and were without food for 12 hours before the test. A double-lumen Dreiling tube (Davol) was passed orally and the tip of the tube was positioned at the ligament of Treitz under fluoroscopic observation. An intravenous infusion of normal saline was started and continued at $0.5 \mathrm{ml} / \mathrm{min}$ throughout each experiment.

During the first 10 to 15 minutes after intubation the stomach and duodenum were drained by gentle continuous aspiration using hand-operated syringes and the specimens discarded. Then a tandem secretin test was done on each subject as described by Dreiling et al (1955) and Dreiling and Janowitz (1960). A 20-minute basal period was begun, during which both gastric and duodenal secretions were collected. At the end of the basal period each subject was administered 1.0 unit of Boots secretin (Boots Pure Drug Co, Ltd, Nottingham, England; WarrenTeed Company) per kg body weight intravenously. All tests were conducted with the same secretin preparation at the same dose. Following secretin administration four consecutive 20-minute collections of gastric and duodenal secretions were made. The same procedure was followed for the second part of the test except that each subject smoked seven nonfiltered Camel cigarettes over the 100 minutes of the test, or approximately four cigarettes per hour. Gastric secretions underwent $p \mathrm{H}$ and volume determinations, and duodenal collections were analysed for volume, $p \mathrm{H}$, bicarbonate concentration, and amylase content. Secretin test results during smoking were compared to results from nonsmoking periods, with particular reference to total volume of juice collected, volume per $\mathrm{kg}$ body weight, bicarbonate output, and maximum bicarbonate concentration. Data for heavy smokers during both smoking and non-smoking periods were compared to those for light smokers. Results were assessed statistically by means of univariate and multivariate analyses of variance (Morris, 1967).

Boots secretin was selected for these double secretin tests because of its ready availability and its common use in tests of human pancreatic exocrine function. With time we became aware, both from the single secretin test control group and the double secretin test group, that values for secretin-stimulated pancreatic fluid volume and bicarbonate concentration were low in our subjects compared with the usual standards (Dreiling and Janowitz, 1962). However, another recent report (Bordalo and Teixeira, 1967) gave values for total volume $(\mathrm{ml} / \mathbf{k g})$, and bicarbonate concentration, with Boots secretin (1.0 unit $/ \mathbf{k g}$ ), which were closer to our values. Suspecting some problem with secretin potency in the light of an apparent gradual decline in reported values over several years, we contacted Boots Pure
Drug Company and were informed that our suspicions were correct and a re-assay of the preparation was being undertaken. Because of these problems Warren-Teed recalled Boots secretin from the American market but agreed to supply us with secretin from the same batch in use to enable completion of this study. Re-assay of our secretin by the Boots laboratories has shown it to be $60-70 \%$ of expected potency.

\section{Results}

1 CONTROL GROUP

After secretin stimulation, the mean volume of fluid recovered during the entire 80 -minute period was $233.8 \pm 31.9 \mathrm{ml}$ (standard error of the mean); mean volume per kilogram body weight was $2.9 \pm 0.4$ $\mathrm{ml} / \mathrm{kg}$. Mean total (80-minute) bicarbonate output was $15.1 \pm 1.9$ m-equiv; mean hourly output of bicarbonate was $11.5 \pm 1.5 \mathrm{~m}$-equiv/hr. The mean maximum bicarbonate concentration was $83.0 \pm 7 \cdot 6$ m-equiv/l.

\section{TEST GROUP}

\section{Light smokers}

In secretin tests, non-smoking, the mean volume recovered for 80 minutes was $175.6 \pm 22.6 \mathrm{ml}$; the mean volume per kilogram body weight was $2 \cdot 4 \pm$ $0.2 \mathrm{ml} / \mathrm{kg}$. The mean total ( 80 minutes) bicarbonate output was $11.1 \pm 1.8 \mathrm{~m}$-equiv; the mean hourly bicarbonate output was $8.4 \pm 1.3 \mathrm{~m}$-equiv/hr. The mean maximum bicarbonate concentration was 79.4 $\pm 8.7 \mathrm{~m}$-equiv/l. None of these values were significantly different from those of the control group. In secretin tests, smoking, the mean volume recovered for $80 \mathrm{~min}$ was $106.9 \pm 11.8 \mathrm{ml}$; the mean volume per kilogram body weight was $1.5 \pm 0.2 \mathrm{ml} / \mathrm{kg}$. The mean total $(80 \mathrm{~min})$ bicarbonate output was $7 \cdot 4 \pm$ 1.3 m-equiv; the mean hourly bicarbonate output was $5.5 \pm 1.0 \mathrm{~m}$-equiv/hr. The mean maximum bicarbonate concentration was $76 \cdot 3 \pm 7 \cdot 1$ m-equiv/l. In every light smoker, smoking caused a significant $(P<0.001)$ decrease in both volume of secretion and bicarbonate output.

\section{Heavy smokers}

In secretin tests, non-smoking, the mean volume for 80 min was $140.3 \pm 16.5 \mathrm{ml}$; the mean volume per kilogram body weight was $1.9 \pm 0.3 \mathrm{ml} / \mathrm{kg}$. The mean total $(80 \mathrm{~min})$ bicarbonate output was $9.5 \pm$ 1.2 m-equiv. The mean hourly bicarbonate output was $7.1 \pm 0.9 \mathrm{~m}$-equiv/ $\mathrm{hr}$. The mean maximum bicarbonate concentration was $86.2 \pm 4.9$ m-equiv/l. Values for volume and bicarbonate output were significantly $(\mathrm{P}<0.01)$ less than in the control subjects. 


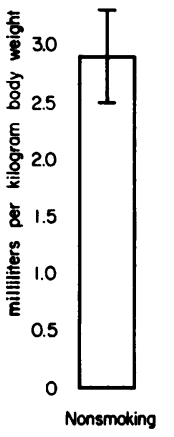

Controls

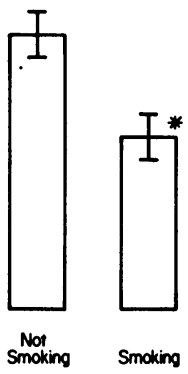

Light Smokers

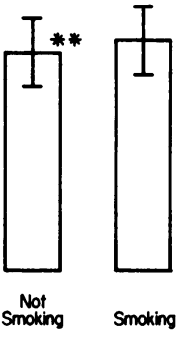

Heavy Smokers

Fig. 1 Volume of pancreatic secretion after secretin.

*Significantly different from non-smoking tests.

In secretin tests, smoking, the mean volume for 80 min was $146.9 \pm 18.7 \mathrm{ml}$; the mean volume per kilogram body weight was $2.0 \pm 0.3 \mathrm{ml} / \mathrm{kg}$. The mean total $(80 \mathrm{~min})$ bicarbonate output was $10.7 \pm 1.4$ m-equiv; the mean hourly bicarbonate output was $8.07 \pm 1.0 \mathrm{~m}$-equiv $/ \mathrm{hr}$. The mean maximum bicarbonate concentration was $88.3 \pm 4.6 \mathrm{~m}$-equiv/l. None of these values were significantly different from comparable values during the non-smoking test in these subjects.

In general, no significant changes were observed in bicarbonate concentration in any of the duodenal specimens obtained after secretin stimulation. Therefore, the observed changes in volume (Fig. 1) were accompanied by changes in bicarbonate output (Fig. 2). Amylase levels in duodenal specimens after secretin administration were not consistently or significantly altered by smoking.

\section{Discussion}

Cigarette smokers have a higher incidence of duodenal ulcers than non-smokers (Edwards et al, 1959; Hammond, 1964; Monson, 1970) and ulcer disease morbidity is directly related to the quantity and duration of smoking (Edwards et al, 1959; Hammond, 1964). Inhibition of pancreatic secretion in dogs by nicotine (Konturek et al, 1971) suggested a possible mechanism whereby cigarette smoking could promote duodenal ulcer formation. Our present results demonstrate that cigarette smoking also inhibits pancreatic secretion in man; presumably, nicotine is the agent which produces the inhibition. In light smokers values from the first of the secretin tests (no smoking) were not statistically distinguish-

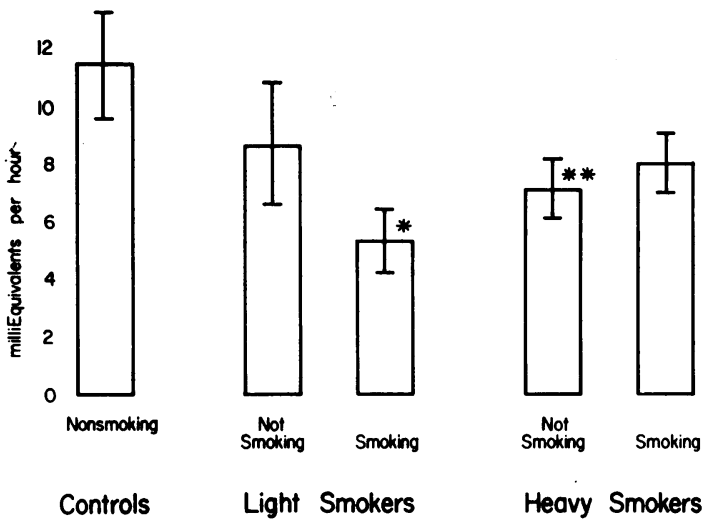

Fig. 2 Pancreatic output of bicarbonate after secretin.

* Significantly different from non-smoking controls.

able from those of the control group; however, smoking significantly inhibited the volume of pancreatic secretion and bicarbonate output in these light smokers. In the heavy smokers there was no inhibition of pancreatic secretion during smoking; however, heavy smokers exhibited depressed pancreatic responses to secretin during the non-smoking period compared with control subjects. The data suggest that smoking, and presumably the nicotine in cigarette smoke, decreases pancreatic secretion in light smokers, whereas secretion in heavy smokers is chronically depressed so that acute smoking episodes fail to bring about further inhibition in the latter group. The reason for the response in heavy smokers is not known; perhaps heavy smoking over a long period of time permits an adaptation to occur. When individuals first begin smoking and inhaling, they experience nausea, occasional vomiting, palpitations, and diaphoresis-all symptoms of mild nicotine intoxication (Goodman and Gilman, 1965). After people become established smokers, these symptoms do not occur and presumably some adaptation has developed.

With inhalation, $90 \%$ of the nicotine in cigarette smoke is absorbed (Goodman and Gilman, 1965). Our subjects smoked regular, non-filtered Camel cigarettes with an approximate nicotine content of $1.6 \mathrm{mg}$ per cigarette (Federal Trade Commission, USA, 1969), at the rate of four cigarettes per hour. Thus, each subject received approximately $5.7 \mathrm{mg}$ nicotine per hour. This dose is comparable to that producing pancreatic inhibition in dogs (Konturek et al, 1971).

The mechanism by. which nicotine interferes with pancreatic secretion is not known. Edmunds (1909) 
reported that nicotine (in massive doses) inhibited secretin-stimulated pancreatic secretion in anaesthetized dogs and speculated that the effect was mediated by adrenalin release. Subsequently, nicotine has been shown to release catecholamines (Westfall, 1965) but nicotine has a variety of effects, including autonomic ganglionic stimulation and blockade (Goodman and Gilman, 1965) and the release of histamine (Goodman and Gilman, 1965), 5-hydroxytryptamine (Burks and Long, 1967), and gastrin (Olbe and Elwin, 1965). However, all of the effects of nicotine mentioned above are induced by large doses of the drug and are accompanied by altered gastric secretion which has not been observed in our dog or human experiments.

Dreiling and Janowitz $(1955,1960)$ demonstrated that double secretin tests gave results for volume secretion and bicarbonate output that varied from first to second test by less than $10 \%$. Where statistical significance is indicated, our results showed greater than a $10 \%$ change; therefore smoking appears to have caused a greater change in light smokers than could be expected from what is seen merely by performing a second secretin test.

Lagerlöf, Schütz, and Holmer (1966) found that $20 \%$ of duodenal fluid was lost down the intestine during secretin tests, to which one should add that the intestine absorbs approximately $30 \mathrm{ml}$ of water per hour (Lagerlöf, 1966) and 2 m-equiv of bicarbonate per hour (Lagerlöf, Rudewald, and Perman, 1960). However, Dreiling and Janowitz (1962) found that recovery of duodenal fluid was essentially complete. Since we followed Dreiling and Janowitz in method and equipment, we assumed that our recovery of duodenal fluid was close to complete also.

Gastric secretory activity was unrelated to our results because in this preparation the stomach was constantly aspirated and kept empty, and because secretin inhibits gastric secretion. Furthermore, smoking does not consistently affect gastric secretion. A recent study (Petersen, 1970) again demonstrated that mean histamine-stimulated gastric acid secretion was higher in a group of duodenal ulcer patients when compared to matched non-ulcer controls, and that there was in addition an increase in secretin-stimulated pancreatic secretion that was proportional to the increase in acid secretion. Smokers have not demonstrated increased acid secretion and in our group appear to have a disproportionate decrease in secretin-stimulated pancreatic secretion, which may be a factor in the development of duodenal ulcer even though acid secretion is not elevated. In this regard, it would be of interest to investigate gastric secretory capacity in a large group of light and heavy smokers with duodenal ulcers to determine if their mean gastric acid secretion is lower than that of non-smokers with duodenal ulcers.

This study was aided by a grant from the American Medical Association Education and Research Foundation. The authors wish to thank Richard Manner, MD, of Warren-Teed Pharmaceuticals for a supply of Boots secretin; Howard K. Thompson, $\mathrm{Jr}, \mathrm{MD}$, of Baylor College of Medicine, for assistance in statistical analysis; and Mrs Louise Wyss for technical assistance.

References

Bordalo, O., and Teixeira, M.S. (1967). A comparison of the standard and 'maximal' secretin test findings in normal subjects. Amer. J. Gastroent., 48, 328-333.

Burks, T. F., and Long, J. P. (1967). Release of 5-hydroxytryptamine from isolated dog intestine by nicotine. Brit. J. Pharmacol., 30, 229-239.

Debas, H. T., Cohen, M. M., Holubitsky, I. B., and Harrison, R. C. (1971). Effect of cigarette smoking on human gastric secretory responses. Gut, 12, 93-96.

Doll, R., Jones, F. A., and Pygott, F. (1958). Effect of smoking on the production and maintenance of gastric and duodenal ulcers. Lancet, 1, 657-662.

Dreiling, D. A., and Janowitz, H. D. (1960). Inhibitory effect of new anticholinergics on the basal and secretin-stimulated pancreatic secretion in patients with and without pancreatic disease. Amer. J. dig. Dis., 5, 639-654.

Dreiling, D. A., Janowitz, H. D. (1962). The measurement of pancreatic secretory function.In Ciba Foundation Symposium on the Exocrine Pancreas, edited by A. V. S. de Reuck and M. P. Cameron, pp. 225-252. Churchill, London.

Dreiling, D. A., Janowitz, H. D., and Halpern, M. (1955). The effect of a carbonic anhydrase inhibitor, Diamox, on human pancreatic secretion. Gastroenterology, 29, 262-279.

Edmunds, C. W. (1909). The antagonism of the adrenal glands against the pancreas. J. Pharmacol exp. Ther., 1, 135-150.

Edwards, F., McKeown, T., and Whitfield, A. G. W. (1959). Association between smoking and disease in men over 60 . Lancet, 1 , 196-200.

Federal Trade Commission (U.S.A.), March, 1969.

Goodman, L. S., and Gilman, A. (1965). The Pharmacological Basis of Therapeutics, 3rd ed., MacMillan, New York.

Hammond, E. C. (1964). Smoking in relation to mortality and morbidity. Findings in first $\mathbf{3 4}$ months of follow-up in a prospective study started in 1959. J. nat. Cancer Inst., 32, 1161-1188.

Konturek, S. J., Rodecki, T., Thor, P. et al (1972). Effects of nicotine on gastric secretion and ulcer formation in cats. Proc. Soc. exp. Biol. (N.Y.), in press.

Konturek, S. J., Solomon, T. E., McCreight, W. G., Johnson, L. R., and Jacobson, E. D. (1971). Effects of nicotine on gastrointestinal secretions. Gastroenterology, 60, 1098-1105.

Lagerlöf, H. O. (1966). Determinazione della secrezione pancreatica esterna. Minerva Med., 57, 1420-1424.

Lagerlöf, H. O., Rudewald, M. B., and Perman, G. (1960). The neutralization process in duodenum and its influence on the gastric emptying in man. Acta med scand., 168, 269-284.

Lagerlöf, H. O., Schütz, H. B., and Holmer, S. (1967). A secretin test with high doses of secretin and correction for incomplete recovery of duodenal juice. Gastroenterology, 52, 67-77.

Lee, K. S., and Gruber, C. M., Jr. (1952). The effect of nicotine on the production of peptic ulcers in histamine treated dogs. Arch. int. Pharmadocyn., 90, 462-465.

Monson, R. R. (1970). Cigarette smoking and body form in peptic ulcer. Gastroenterology, 58, 337-344.

Morris, D. F. (1967). Multivariate Statistical Methods, ch. 5. McGraw Hill, New York.

Olbe, L., Elwin, C. E. (1965). Effects of tobacco smoking and nicotine on gastric acid secretion in dogs. In Tobacco Alkaloids and Related Compounds (Wenner-Gren Center International Symposium Series, Vol. 4), edited by U. S. von Euler, pp. 273-275. MacMillan, New York. 
Petersen, H. (1970). Relationship between gastric and pancreatic secretion in patients with duodenal ulcer. Scand. J. Gastroent., 5, 321-326.

Piper, D. W., and Raine, J. M. (1959). Effect of smoking on gastric secretion. Lancet, 1, 696-698.

Robert, A., Stowe, D. F., and Nezamis, J. E. (1972). Possible relationship between smoking and peptic ulcer. Nature (Lond.), in press.

Toon, R. W., Cross, F. S., and Wangensteen, O. H. (1951). Effect of inhaled cigarette smoke on production of peptic ulcer in the dog. Proc. Soc. exp. Biol. (N. Y.), 77, 866-869.

Westfall, T. C. (1965). Tobacco alkaloids and the release of catecholamines. In Tobacco Alkaloids and Related Compounds (Wenner-Gren Center International Symposium Series, Vol. 4), edited by U.S. von Euler, pp. 179-201. MacMillan, New York. Wilkinson, A.R., and Johnston, D. (1971). Inhibitory effect of cigarette smoking on gastric secretion stimulated by pentagastrin in man. Lancet, 2, 628-632. 